\title{
PENANGANAN DAERAH RAWAN LONGSORAN PADA KM 359+600 LINTAS DAOP 5 PURWOKERTO DENGAN METODE SHOTCRETE
}

\author{
Calvin Andika, JRC Hosang, Nur'aini Boer \\ PTDI-STTD
}

\begin{abstract}
ABSTACT
Landslides in the area traversed by the railroad will have an impact on the less than optimal performance of the train. On the Notog - Kebasen Station route at kilometer 359+600, it is an area that is prone to landslides. This can lead to PLH (Extraordinary Great Event). To be able to solve this, a method is needed to improve areas prone to landslides such as methods of improving cliff stability or shotcrete. Through the results of the analysis carried out, it can be concluded that this landslide was caused by a slope angle with a steepness of 70-8-degrees with a height of 11 meters. Then the existing drainage system is also damaged, so that the weight of the soil increases and the soil pressure also increases.
\end{abstract}

Keywords: Landslide, train, drainage, shotcrete.

\begin{abstract}
ABSTRAK
Longsornya tanah di wilayah yang dilewati oleh rel kereta api akan berdampak pada kurang maksimalnya kinerja dari kereta tersebut. Pada lintasan Notog - Stasiun Kebasen di kilometer 359+600 merupakan wilayah yang rawan akan longsoran. Hal ini dapat menyebabkan terjadinya PLH (Peristiwa Luar Biasa Hebat). Untuk dapat menyelesaikan ini maka diperlukan metode untuk memperbaiki wilayah yang rawan longsor seperti metode perbaikan stabilitas tebing ataupun shotcrete. Melalui hasil analisis yang dilakukan, dapat disimpulkan bahwa longsoran ini diakibatkan oleh sudut lereng dengan kecuraman 70-8- derajat dengan ketinggian 11 meter. Kemudian sistem drainase yang ada juga mengalami kerusakan, sehingga dapat berat tanah bertambah dan tekanan tanah ikut meningkat.
\end{abstract}

Kata kunci: Longsor, kereta, drainase, shotcrete.

\section{PENDAHULUAN}

Prasarana kereta api termasuk salah satu faktor utama dalam kelancaran pengoperasian kereta api, sehingga kondisi dari prasarana harus laik dan aman untuk dilalui kereta api. Apabila tidak laik dapat secara langsung berpengaruh terhadap perjalanan kereta api. Peranan dari prasarana memegang kedudukan yang sangat penting karena prasarana kereta api merupakan salah satu faktor utama dalam kelancaran pengoperasian kereta api, maka secara langsung akan mempengaruhi pengoperasian perjalanan kereta api dan perlu adanya perawatan yang intensif.

Secara umum wilayah studi praktik kerja lapangan lintas Purwokerto - Banjar merupakan daerah yang sebagian besar dikelilingi area persawahan, lereng, tebing dan perbukitan yang bergelombang, sehingga banyak terdapat daerah aliran dan resapan air yang berpengaruh terhadap kondisi struktur tanah yang labil. Pada wilayah studi yaitu petak jalan Notog - Kebasen sendiri adalah lintas galian dengan kondisi tanah labil yang di kedua sisi jalan relnya terdapat tebing bebatuan yang tinggi dan curam yang menjadikan lintas tersebut menjadi daerah titik rawan longsor. Selain itu juga memiliki banyak jalan rel lengkung dengan radius lengkung yang kecil, sehingga untuk keamanan perjalanan kereta api pada lintas tersebut dipasang pembatas kecepatan (taspat).

Antara Stasiun Notog - Stasiun Kebasen pada KM 359+600 adalah daerah rawan terjadinya longsoran, di sisi jalan rel terdapat batu kecil sisa dari longsor dikarenakan hampir pada setiap terjadi 
cuaca buruk dan gempa bumi, terjadi longsoran batu dari tebing bebatuan dan dikhawatirkan longsoran batu tersebut memasuki daerah ruang bebas kereta api yang menimbulkan masalah baru berupa terganggunya perjalanan kereta api, sehingga perlu adanya upaya peningkatan kondisi jalan rel tersebut. Penanganan yang dilakukan saat ini adalah dibuatnya pos penjagaan kecil 24 jam yang bertugas untuk membersihkan dan mengamankan di daerah ruang bebas kereta api pada lintas tersebut dari sisa sisa batu jika terjadi longsoran namun dinilai belum efektif dan belum ada penanganan lebih lanjut untuk mencegah longsor di lintas tersebut terjadi kembali. Sehubungan dengan hal tersebut dalam rangka meningkatkan kualitas pengoperasian yang maksimal yaitu aman, lancar dan selamat, khususnya pada Daop 5 Purwokerto, maka penulis ingin meneliti mengenai bagaimana penanganan daerah rawan longsoran pada KM 359+600 Liantas DAOP 5 Purwekorto.

\section{KAJIAN PUSTAKA}

\section{Faktor Penyebab Longsor}

Menurut Kabul BS. Kontribusi pengurangan kuat geser tanah pada lereng alam yang mengalami longsor disebabkan oleh faktor yang dapat berasal dari alam itu sendiri, erat kaitannya dengan kondisi geologi antara jenis tanah, tekstur (komposisi) dari pada tanah pembentuk lereng sangat berpengaruh terjadinya longsoran, misalnya sensivitas sifat-sifat tanah lempung, adanya lapisan tanah shale, loess, pasir lepas, dan bahan organik. Bentuk butiran tanah (bulat, ataupun tajam) berpengaruh terhadap friksi yang terjadi dalam tanah, pelapisan tanah, pengaruh gempa, geomorfologi (kemiringan daerah), iklim, terutama hujan dengan intensitas tinggi atau sedang, dengan durasi yang lama di awal musim hujan, atau menjelang akhir musim hujan, menimbulkan perubahan parameter tanah yang berkaitan dengan pengurangan kuat gesernya. Menurut Pusat Vulkanologi dan Mitigasi Bencana Geologi, (2005) tanah longsor dapat terjadi karena faktor alam dan faktor manusia sebagai pemicu terjadinya tanah longsor, yaitu:

a) Faktor Alam

Meliputi lereng terjal yang diakibatkan oleh patahan dan lipatan kulit bumi, erosi dan pengikisan, daerah longsoran lama, ketebalan tanah pelapukan bersifat lembek, butiran halus, jenuh karena air hujan, adanya retakan karena proses alam (gempa bumi, tektonik), air (hujan di atas normal, susut air cepat, banjir, aliran air bawah tanah pada sungai lama), lapisan batuan yang kedap air miring ke arah yang berfungsi sebagai bidang longsoran.

b) Faktor Manusia

Lereng menjadi terjal akibat pemotongan lereng dan penggerusan oleh air saluran di tebing, tanah lembek dipicu oleh perubahan tata lahan menjadi lahan basah, adanya kolam ikan, genangan air, retakan akibat getaran mesin ledakan, beban massa yang bertambah dipicu oleh beban kendaraan, bangunan dekat tebing, tanah kurang padat karena material urugan atau material longsoran lama pada tebing, bocoran air saluran, luapan air saluran, kolam ikan, penggundulan hutan sehingga terjadi pengikisan oleh air permukaan.

\section{Metoda Perbaikan Stabilitas Tebing}

Menurut Hary C. H (2012) Perbaikan stabilitas tebing umumnya dilakukan untuk mereduksi gaya-gaya yang menggerakkan, menambah tahanan geser tanah atau keduanya. Gaya - gaya yang menggerakkan dapat direduksi dengan cara :

a) Menggali material yang berada pada zona tidak stabil,

b) Mengurangi tekanan air pori dengan mengalirkan air pada zona tidak stabil.

Menurut Abramson et la (1994) Gaya - gaya yang menahan gerakan longsor dapat ditambah dengan cara :

a) Drainase yang menambah kuat geser tanah,

b) Menghilangkan lapisan lemah atau zona berpotensi longsor yang lain,

c) Membangun struktur penahan atau sejenisnya,

d) Melakukan perkuatan tanah di tempat, 
e) Penanganan secara kimia atau yang lain (misalnya mengeraskan tanah) untuk menambah kuat geser tanah.

Sebelum pemilihan metoda stabilitas dipilih, penyebab ketidakstabilitas lereng harus diteliti lebih dulu, karena sering terdapat lebih dari satu faktor penyebab yang memicu ketidakstabilan lereng. Berikut ini akan dibahas macam - macam metoda perbaikan lereng dengan cara :

a) Merubah geometri tebing atau lereng,

b) Mengontrol drainase dan rembesan,

c) Pembuatan struktur untuk stabilisasi,

d) Pembongkaran dan pemindahan,

e) Perlindungan permukaan lereng.

\section{Sejarah Shotcrete}

Shotcrete pertama kali ditemukan oleh Carl Ethan Akeley (1864 - 1926) pada 1910. Arsitek Amerika ini telah terinspirasi untuk mewujudkan reproduksi yang nyata dari dinosaurus untuk sebuah taman wisata. Mengingat ukuran struktur yang cukup besar, ia mempunyai ide untuk mengembangkan "cement gun" mesin yang memungkinkan penyemprotan dari cementitious mortar, ide awal ini menyebabkan munculnya istilah "shotcrete".

Menurut American Concrete Institute (ACI), Shotcrete dapat didefinisikan sebagai mortar atau beton yang diberikan tekanan dengan kecepatan tinggi. Komponen campurannya terdiri atas semen, pasir, agregat, air, dan tambahan admixtures.

Perbedaan shotcrete dengan beton normal dapat dilihat dari 3 hal :

a) Ukuran agregat maksimum yang digunakan

b) Proses pelaksanaannya

c) Campuran dari shotcrete bisa kering atau basah.

\section{METODE}

Langkah awal dalam rencana penelitian ini adalah dengan melakukan pengumpulan data baik yang bersifat kuantitatif maupun kualitatif. Data tersebut terdiri dari data sekunder dan data primer yang digunakan sebagai petunjuk dan pedoman kinerja pelayanan Depo Induk Kereta Purwokerto. Penelitian akan dilaksanakan di DOAP 5 Purwokerto dengan pengumpulan data dan informasi berdasarkan buku-buku referensi maupun peraturan yang ada.

\section{PEMBAHASAN}

\section{Penyebab Terjadinya Longsoran}

Pada KM 359+600 - KM 361+200 antara Stasiun Notog - Stasiun Kebasen adalah daerah rawan longsoran dan terjadi karena kondisi tanah pada daerah tersebut mengalami pergerakan tanah yang cukup cepat dan bersifat aktif. Faktor - faktor penyebab terjadinya longsoran akibat pergerakan lereng pada permukaan tanah adalah:

a) Keadaan Lereng

Sudut lereng cukup curam yakni sekitar 70 - 80 derajat dengan puncak ketinggian 11 meter dan keadaan medan terdiri dari pegunungan dan perbukitan serta lahan bekas persawahan dan rawa dengan kondisi kurang mantap.

b) Drainase

Adanya aliran air atau drainase merupakan faktor penyumbang terbesar yang akan mengakibatkan berkurangnya kuat geser tanah. Bila Drainase mampet dan tidak bisa mengalirkan air maka tanah dasar akan mendorong lereng dan mengalami penurunan yang diakibatkan adanya aliran air tersebut dan sangat berpotensi menyebabkan terjadinya longsor.

c) Penanganan yang Telah Dilakukan

Yang telah dilakukan untuk penanganan daerah longsoran pada lokasi tersebut adalah dibuatnya pos penjagaan 24 jam untuk mengawasi daerah rawan longsor tersebut jika terjadi 
longsor yang dapat mengganggu perjalanan kereta api, maka pos penjagaan tersebut harus melapor ke stasiun terdekat untuk ditangani lebih lanjut. Penulis menilai penanganan ini kurang efektif karena hanya dengan penanganan seperti ini, dapat beresiko besar terjadinya PLH (Peristiwa Luar Biasa Hebat), gambar ini diambil pada tanggal 19 mei 2015.

\section{Dampak Terjadinya Longsoran}

Faktor yang mempengaruhi longsoran diantaranya adalah beban yang melebihi daya dukung tanah, kadar air yang tinggi sehingga menurunkan daya dukung tanah. Selain itu, getaran yang ditimbulkan kereta api pada saat melewati tubuh baan yang labil juga dapat mengakibatkan gerakan tanah akibat dari beban kereta api yang diberikan pada tanah yang labil. Sehingga lereng pada permukaan tanah akan mengalami penurunan yang mengakibatkan terjadinya longsoran karena daya dukung tanah tersebut tidak mampu menahan dan memikul berat beban sendiri maupun beban dari luar yaitu beban yang diakibatkan karena getaran kereta api pada saat melintas. Dari hasil longsoran yang disebabkan, dapat menyebabkan PLH (Peristiwa Luar Biasa Hebat) pada kereta api serta ketidaknyamanan pada perjalanan kereta api yang melintas pada lintas tersebut.

\section{Analisa Penyelidikan Tanah}

Penyelidikan tanah dilakukan untuk mengetahui jenis dan sifat parameter tanah. Kegiatan penyelidikan tanah ada dua cara, yaitu : dengan pengamatan visual di lapangan dan uji laboratorium. Cara yang dipilih penulis dalam menyelidiki tanah di lokasi tersebut adalah dengan menggunakan hasil uji laboratorium untuk mendapatkan hasil yang akurat.

a) Data Pengujian Boring

Pengujian sampel tanah boring dilakukan pada KM 359+600 karena pada titik ini adalah titik daerah rawan longsor dan berada langsung pada kontruksi rencana dinding penahan tanah yang akan dibangun nantinya.

Tabel 1. Hasil Bore Log

\begin{tabular}{|c|l|c|}
\hline \multicolumn{2}{|c|}{ Hasil Bore Log } & N SPT \\
\hline Kedalaman $(\mathrm{m})$ & \multicolumn{1}{|c|}{ Jenis Tanah } & - \\
\hline $0-0,5$ & Lempung kepasiran mengandung boulder, coklat & 6 \\
\hline $0,5-4,8$ & Lanau kepasiran plastisitas tinggi, mengandung krikil, lunak, coklat & $3-5$ \\
\hline $4,8-16$ & $\begin{array}{l}\text { Lempung lunak, mengandung sampah, abu-abu sampai abu-abu } \\
\text { kecoklatan }\end{array}$ & 6 \\
\hline $16-25$ & $\begin{array}{l}\text { Lempung kepasiran, teguh sampai kaku, mengandung sedikit pasir halus, } \\
\text { abu-abu }\end{array}$ & 6 \\
\hline
\end{tabular}

Dari hasil pengujian sampel tanah boring diatas didapat bahwa pada kedalaman $0-0,5 \mathrm{~m}$ merupakan tanah yang bersifat lempung (Clay) dan pada kedalaman 0,5-4,8 m merupakan tanah yang bersifat lanau (Silt) dan pada kedalaman selanjutnya yaitu pada kedalaman 4,8 - $25 \mathrm{~m}$ adalah tanah yang bersifat lempung (Clay).

b) Data tanah hasil uji laboratorium

Adapun data tanah yang didapatkan penulis dari hasil pengujian laboratorium pada titik boring yang telah dilakukan adalah sebagai berikut:

Tabel 2. Data Tanah Hasil Uji Laboratorium

\begin{tabular}{|c|c|c|c|c|c|c|c|c|c|}
\hline \multirow[b]{2}{*}{$\begin{array}{l}\text { Depth } \\
\text { (m) }\end{array}$} & \multirow{2}{*}{$\begin{array}{c}\text { Berat } \\
\text { Isi } \\
\text { Tanah } \\
\text { Y } \\
\left(\mathrm{gr}^{2} \mathrm{~cm}^{3}\right) \\
\end{array}$} & \multirow[b]{2}{*}{$\begin{array}{c}\text { Berat } \\
\text { Jenis } \\
\text { Tanah } \\
\text { (Gs) }\end{array}$} & \multirow[b]{2}{*}{$\begin{array}{c}\text { Kadar } \\
\text { Air (w) } \\
\%\end{array}$} & \multirow[b]{2}{*}{$\begin{array}{l}\text { Porosity } \\
\text { (n) }\end{array}$} & \multirow[b]{2}{*}{$\begin{array}{l}\text { Void } \\
\text { Ratio } \\
\text { (e) }\end{array}$} & \multicolumn{3}{|c|}{ Plasticity Test } & \multirow[b]{2}{*}{$\begin{array}{c}\text { Shrinkage } \\
\text { Limits } \\
\text { Test }\end{array}$} \\
\hline & & & & & & LL \% & PL\% & PI \% & \\
\hline$-4,00$ & 1,72 & 2,69 & 48,26 & 56,85 & 1,32 & 45,80 & 30,00 & 14,80 & 12,97 \\
\hline$-8,00$ & 1,62 & 2,61 & 49,36 & 58,34 & 1,40 & 60,50 & 28,57 & 31,93 & 11,21 \\
\hline$-14,00$ & 1,60 & 2,61 & 62,04 & 62,12 & 1,64 & 69,00 & 35,38 & 33,62 & 18,94 \\
\hline$-17,00$ & 1,66 & 2,66 & 64,36 & 61,39 & 1,63 & 66,80 & 36,03 & 30,77 & 18,37 \\
\hline$-24,50$ & 1,65 & 2,66 & 59,72 & 61,11 & 1,67 & 56,00 & 29,25 & 26,75 & 17,08 \\
\hline
\end{tabular}




\section{Analisa Pemilihan Pemasangan Dinding Penahan Tanah yang Tepat}

a) Dinding penahan tanah gravitasi

Terbuat dari beton tak bertulang atau pasangan batu, sedikit tulangan diberikan pada permukaan dinding untuk mencegah retakan permukaan. Kekuatan dinding gravitasi sepenuhnya tergantung dari berat sendiri dinding ini. Dinding gravitasi berbentuk trapesium, semakin tinggi tebing yang ingin dipasang dinding gravitasi, semakin lebar tebal dinding gravitasi tersebut sehingga dinding penahan tanah gravitasi tidak cocok untuk dipasang di lokasi KM 359+600 yang areanya kurang luas.

b) Dinding kantilever

Terdiri dari kombinasi dinding dan fondasi beton bertulang yang berbentuk T. Ketebalan dinding penahan tanah ini relative tipis dan diberi tulangan secara penuh untuk menahan momen dan gaya lintang yang bekerja. Dinding kantilever merupakan dinding penahan tanah beton bertulang ekonomis dan mudah dalam pelaksanaannya, namun dinding jenis ini hanya cocok digunakan untuk menahan timbunan tanah dengan ketinggian 2,5 - 6 meter, sehingga dinding ini tidak cocok untuk digunakan pada lokasi km 359+600 yang puncak ketinggian tebingnya mencapai 11 meter.

c) Dinding penahan tanah shotcrete

Shotcrete banyak diaplikasikan karena cocok digunakan di berbagai tipe batuan kecuali pasir, mudah dioperasikan karena hanya butuh 1 orang operator, dapat mengeras dengan sangat cepat. Pada beberapa percobaan shotcrete dengan penggunaan campuran tambahan, shotcrete dapat mengeras dalam waktu 1 jam. Tingkat kekuatannya juga melebihi campuran beton yang dikenal oleh orang awam. Dalam waktu $1-6$ jam, sebuah dinding yang disemprot dengan shotcrete mampu menahan tabrakan dari alat berat sejenis wheel loader, dan hanya tergores sedikit di permukaannya, serta mampu menahan getaran peledakan yang mempunyai tekanan dari puluhan sampai ratusan ribu psi per detik.. Kelebihan shotcrete adalah:

1) Tidak memerlukan kaki beton.

2) Ketebalannya tipis hanya $75 \mathrm{~mm}$.

3) Mempunyai kekuatan tarik yang besar.

4) Tahan terhadap air.

5) Dapat mengatasi tebing dengan kelandaian mencapai $90^{\circ}$.

Sehingga dinding penahan tanah shotcrete sangat cocok untuk dipasang pada lokasi km $359+600$.

Tabel 3. Kelebihan dan Kekurangan Dinding Penahan Tanah

\begin{tabular}{|c|c|c|}
\hline $\begin{array}{l}\text { Jenis Dinding } \\
\text { Penahan Tanah }\end{array}$ & Kelebihan & Kekurangan \\
\hline \multirow{3}{*}{$\begin{array}{l}\text { Dinding Penahan } \\
\text { Tanah Gravitasi }\end{array}$} & $\begin{array}{l}\text { Prosedur kontruksi yang mudah dan } \\
\text { cepat }\end{array}$ & $\begin{array}{l}\text { Membutuhkan ruang yang cukup } \\
\text { besar di bagian belakang dinding } \\
\text { untuk pemasangan penjangkaran }\end{array}$ \\
\hline & $\begin{array}{c}\text { Muka dinding yang dibuat berbagai } \\
\text { bentuk dan tekstur untuk } \\
\text { perkembangan estetika }\end{array}$ & Tidak Ekonomis \\
\hline & $\begin{array}{c}\text { Tidak membutuhkan ruang yang } \\
\text { besar di bagian depan struktur untuk } \\
\text { keperluan kontruksi }\end{array}$ & \\
\hline \multirow{3}{*}{ Dinding Kantilever } & Ketebalannya relatif tipis & $\begin{array}{l}\text { Membutuhkan ruang yang cukup } \\
\text { besar di bagian belakang dinding } \\
\text { untuk pemasangan penjangkaran }\end{array}$ \\
\hline & $\begin{array}{l}\text { Diberi momen untuk menahan gaya } \\
\text { lintang yang bekerja }\end{array}$ & $\begin{array}{c}\text { Ketinggiannya tidak bisa lebih dari } 6 \\
\text { meter }\end{array}$ \\
\hline & harga relatif murah atau ekonomis & \\
\hline
\end{tabular}




\begin{tabular}{|c|c|c|} 
& Tidak memerlukan kaki beton & Biaya pembuatan shotcrete mahal \\
\cline { 2 - 3 } & Ketebalannya tipis hanya 75mm & Tidak bisa digunakan lagi jika pecah \\
\cline { 2 - 3 } $\begin{array}{c}\text { Dinding Penahan } \\
\text { Tanah Shotcrete }\end{array}$ & $\begin{array}{c}\text { Mempunyai kekuatan tarik yang } \\
\text { besar }\end{array}$ & $\begin{array}{c}\text { Tidak ada tanda - tanda ketika hampir } \\
\text { terjadi keruntuhan pada struktur }\end{array}$ \\
\cline { 2 - 3 } & Tahan terhadap air & $\begin{array}{c}\text { Tidak dapat diaplikasikan pada } \\
\text { struktur berupa pasir }\end{array}$ \\
\cline { 2 - 3 } & $\begin{array}{c}\text { Dapat mengatasi kelandaian } \\
\text { mencapai } 90^{\circ}\end{array}$ & \\
\hline
\end{tabular}

\section{Analisa Pemasangan Dinding Penahan Tanah dengan Metode Shotcrete}

Metode penanganan longsor di wilayah studi adalah metode penggunaan dinding penahan tanah sebagai perbaikan tebing. Dinding yang dimaksud adalah dengan menggunakan metode Shotcrete, Alat yang diperlukan untuk pemasangan dinding penahan tanah dengan metode shotcrete yaitu:

a) Mesin Shotcrete Turbosol Spraying Machine tipe TSB 215

b) Rotary Drilling Machine D1

c) Kompressor udara dengan working pressure 7 bar dan kapasitas minimum $250 \mathrm{cfm}$

d) Sumber listrik PLN atau generator $+/-10 \mathrm{kVa} 3$ x $380 \mathrm{~V} / 50 \mathrm{~Hz}$

e) Pompa air dengan working pressure $2-5$ bar dan kapasitas 501/menit.

Adapun bahan dasar material pekerjaan shotcrete terdiri dari :

a) Portland semen

b) Pasir $0-5 \mathrm{~mm}$ yang bersih dan kering

c) Air

d) Wire Mesh atau kawat anyaman

e) Bahan admixture (ex-BASF) untuk memperoleh mutu beton yang diinginkan.

f) Deformed bar

g) Centralizer

\section{Penanggulangan Permanen}

Penanggulangan permanen yang dilakukan yaitu menggunakan metode shotcrete, mempunyai tahapan pelaksanaan pekerjaan yaitu:

a) Persiapan Permukaan

Sebelum dilakukan pekerjaan penyemprotan, permukaan tebing atau bidang yang akan diberi perkuatan perlu dibersihkan terlebih dahulu terhadap berbagai kotoran yang dapat menyebabkan ikatan shotcrete kekuatannya tidak seperti yang diharapkan. Permukaan yang akan diberi tembakan shotcrete perlu dibersihkan hingga kedalaman dasar shotcrete. Persiapan yang dilakukan yaitu:

1) Permukaan lereng yang akan di shotcrete diratakan terlebih dahulu menggunakan alat bantu

2) Permukaan lereng dibersihkan dan dibasahi dengan alat penyemprot udara dan air bertekanan udara.

b) Pembuatan Drainase pada Lereng (untuk perkuatan lereng)

Pada bagian atas dan ujung bawah lereng perlu diberi saluran drainase lereng sebagai saluran pembuangan air dari sekitar lereng. Sistem drainase lereng perlu dipisahkan dari sistem drainase yang sudah ada sehingga aliran air di desain terpisah.

c) Pemasangan Nail

Tahapan umum pelaksanaan pemasangan nail adalah sebagai berikut:

1) Pemboran

Pemboran dilaksanakan dengan sudut $15^{\circ}$ dari arah horizontal dengan sistem "wash boring", kedalaman bor sampai dengan 12 meter dengan diameter $10 \mathrm{~cm}$ atau sesuai yang 
telah ditentukan konsultan perencana. Posisi masing-masing nail yaitu jarak 2 meter arah vertikal dan horizontal.

2) Flushing

Setelah pemboran selesai, lubang bor dicuci sehingga diharapkan semua lumpur sisa pengeboran keluar dari lubang bor. Pencucian dilaksanakan dengan memompakan air ke dalam lubang bor melalui tremie berupa pipa PVC.

3) Pemasukan Deform Bar

Setelah lubang bor bersih dari lumpur, deform bar dimasukkan ke dalam lubang bor. Untuk menjamin posisi deform bar pada tengah-tengah lubang, pada beberapa tempat sepanjang deform bar dibuatkan dan dipasang centralizer.

4) Grouting

Grouting dilaksanakan dengan campuran air semen yang menghasilkan compressive strength atau mutu mortar k225. Karena bahan grouting adalah campuran air dan semen, maka susut tidak bisa dihindari, oleh sebab itu pengulangan grouting (pengisian air semen) kembali ke dalam lubang bor hingga penuh.

d) Pemasangan Kawat Baja (Wire Mesh)

Untuk memperkuat shotcrete diperlukan pemasangan anyaman kawat agar kekuatan tariknya menjadi lebih besar sehingga tidak mengalami runtuh. Dalam proses pemasangan kawat baja (wire mesh), dikaitkan dengan paku yang ditancapkan pada permukaan lereng, dan dibawah tulangan / wire mesh diberi "beton decking" supaya tidak menempel ke permukaan lereng. Beton decking atau biasa disebut dengan tahu beton adalah beton atau spesi yang dibentuk sesuai dengan ukuran selimut beton yang diinginkan. Biasanya berbentuk kotak-kotak atau silinder, Berfungsi untuk menjaga tulangan agar sesuai dengan posisi yang diinginkan. Bisa dibilang berfungsi untuk membuat selimut beton sehingga besi atau tulangan akan selalu diselimuti beton yang cukup, sehingga didapatkan kekuatan maksimal dari bangunan yang dibuat, dan juga menjaga agar tulangan pada beton tidak berkarat (korosi).

e) Permukaan Shotcrete

1) Untuk shotcrete yang tidak terbebani atau struktur dengan pembebanan terbatas, baik untuk interior maupun eksterior, ketebalannya $75 \mathrm{~mm}$. Ketebalan shortcrete harus dipastikan agar memenuhi persyaratan minimum dengan menggunakan alat bantu seperti benang, lidi pengatur ketebalan atau alat bantu lain yang dapat diterima oleh Direksi Pekerjaan. Alat bantu tersebut harus dipasang menonjol tegak lurus terhadap bidang sehingga ketebalan minimum dapat tercapai dan alinyemen terhadap permukaan shotcrete sesuai dengan gambar rencana. Jarak maksimum alat bantu adalah sama dengan jarak antara nail. Bila digunakan benang sebagai alat bantu maka harus dipastikan benang terpasang dengan kencang, lurus, dan ditempatkan sedemikian rupa sehingga memungkinkan dilakukan pengencangan kembali. Benang tersebut harus dilepaskan setelah selesai menempatkan shotcrete.

2) Penempatan atau Penyemprotan Shotcrete

Penempatan shotcrete dilakukan dari bawah ke atas untuk mencegah terjadinya rebound yang berlebihan. Nozzle penyemprot diarahkan pada bidang kerja hingga mencapai ketebalan rencana dan dilakukan secara tegak lurus rebound minimal dan diperoleh kepadatan maksimum. Tulangan harus dipastikan bersih dan shotcrete ditempatkan di belakang tulangan sehingga dapat mencegah terjadinya rongga atau penumpukan pasir kosong.

f) Perbaikan Permukaan

Untuk shotcrete yang memenuhi persyaratan kekuatan namun memiliki permukaan tidak rapi, dapat diperbaiki dengan: 
1) Menyikat permukaan dengan sikat besi untuk membersihkan material

2) Bila shotcrete telah mengeras, persiapan permukaan ditunda selama 24 jam, kemudian permukaan disiapkan dengan sand blast atau tembakan air bertekanan untuk membersihkan semua material. Penyemprotan harus dilakukan dengan tekanan yang tidak terlalu tinggi karena jika digunakan tekanan berlebih, dapat menyebabkan lemahnya ikatan beton.

g) Shotcrete yang Cacat

Shotcrete yang tidak sesuai spesifikasi dan mengalami kegagalan saat diuji, dapat diperbaiki dengan penempatan shotcrete tambahan atau dibongkar untuk diganti dengan shotcrete yang baru.

h) Pemasangan Plat Penguat

Tahapan terakhir dalam pelaksanaan shotcrete adalah pemasangan plat penguat serta pengencangan baut pada ujung deform bar.

i) Perawatan (curing)

Shotcrete dijaga kelembabannya selama 7 hari setelah ditempatkan agar kualitas shotcrete dapat seperti yang diharapkan. Perawatan dilakukan dengan pemberian air untuk menjaga kelembaban shotcrete, namun harus dijaga agar tidak terlalu basah yang dapat menyebabkan lapisan shotcrete terbawa aliran air.

\section{KESIMPULAN}

Berdasarkan analisis dan pembahasan terhadap penanganan longsor di km 359+600 pada lintas amtara Stasiun Notog - Stasiun Kebasen diperoleh kesimpulan berupa penyebab terjadinya longsoran adalah karena sudut lereng yang cukup curam yaitu sekitar 70 - 80 derajat dengan puncak ketinggian mencapai 11 meter. Kemudian sistem drainase di lokasi telah rusak sehingga berpotensi menambah berat tanah dan menyebabkan tekanan tanah bertambah. Terakhir, dampak dari longsoran dan sisa batu hasil longsoran berpotensi mengganggu perjalanan kereta api untuk terjadinya PLH (Peristiwa Luar Biasa Hebat).

\section{DAFTAR PUSTAKA}

1. Anwar, R., Priadi, E., \& Faisal, A. 2013.Pemetaan Daerah Rawan Longsor Das Kapuas Kota Sekadau Kabupaten Sekadau. Jurnal Teknik Sipil, 16(2).

2. Bakri, S., Murtilaksono, K., \& Barus, B. 2019. Identifikasi Dan Analisis Karakteristik Longsor Di Kabupaten Garut. Jurnal Teknik Sipil, 8(2), 68-78.

3. Dwiatmoko, Ir Hermanto, I. P. U. Mstr, Ir Sugiadi Waluyo, Ipu Me, S. T. Widodo, Ipm Mm, Hendry Senjata Perangin-Angin, And Mstr St. Pengujian Prasarana Lrt Jabodebek. Scopindo Media Pustaka, 2021.

4. Ferichi, D. A. 2019.. Peningkatan Kinerja Pola Operasi Pesinyalan Di Stasiun Sidoarjo Daop Viii Surabaya (Doctoral Dissertation, Politeknik Transportasi Darat Indonesia-Sttd).

5. Galan, I., Baldermann, A., Kusterle, W., Dietzel, M., \& Mittermayr, F. 2019. Durability Of Shotcrete For Underground Support-Review And Update. Construction And Building Materials, 202, 465-493.

6. Malmgren, L., Nordlund, E., \& Rolund, S. 2005. Adhesion Strength And Shrinkage Of Shotcrete. Tunnelling And Underground Space Technology, 20(1), 33-48.

7. Naryanto, H. S. 2011. Analisis Risiko Bencana Tanah Longsor Di Kabupaten Karanganyar, Provinsi Jawa Tengah. Jurnal Dialog Dan Penanggulangan Bencana, 2(1), 21-32.

8. Pandiangan, A. M., Hosang, J. R. C., \& Septanto, D. (2019). Upaya Penanganan Pasca Longsor Lintas Purwokerto-Kutoarjo (Studi Kasus Km 423+ 100 Stasiun Ijo-Tambak). Jurnal Perkeretaapian Indonesia (Indonesian Railway Journal), 3(2).

9. Prudencio Jr, L. R. 1998. Accelerating Admixtures For Shotcrete. Cement And Concrete Composites, 20(2-3), 213-219. 
10. Putra, A. P., Septanto, D., \& Praja, S. W. 2018. Handling Of Landslide Prone Areas By Using The Shotcrete Method. Jurnal Perkeretaapian Indonesia (Indonesian Railway Journal), 2(2), 147155.

11. Putra, A. P., Septanto, D., \& Praja, S. W. 2018. Penanganan Daerah Rawan Longsor Dengan Menggunakan Metode Shotcrete. Jurnal Perkeretaapian Indonesia Volume Ii Nomor.

12. Putra, M. S. G. P. (2020). Tanah Longsor Dan Upaya Pencegahannya. Media Sarana Sejahtera.

13. Subhan, S., Murtilaksono, K., \& Barus, B. 2020. Identification And Analysis Of Landslide Characteristics Out Of The Agriculture In Garut Regency. Jurnal Agrista, 24(1), 19-25.

14. Sulistio, S., Rondonuwu, D. M., \& Hanny, P. 2020. Analisis Rawan Bencana Tanah Longsor Di Kecamatan Ratahan Timur Kabupaten Minahasa Tenggara. Spasial, 7(1), 164-175.

15. Wibawa, I. G. S., Wiraga, I. W., Negara, I. S., \& Arya, I. W. (2017). Penyebab Terjadinya Longsor Timbunan Badan Jalan Pada Ruas Jalan By Pass Kediri-Pesiapan. Logic: Jurnal Rancang Bangun Dan Teknologi, 13(3), 101. 